\title{
Do Inferno a Angola fanga: história e mitologia do Quilombo de Palmares no romance gráfico de Marcelo d'Salete
}

\author{
Julio Souto Salom*
}

\section{Ainda ecoam os tambores do Quilombo}

Para entender a importância do romance gráfico Angola fanga, de Marcelo d'Salete (2017), é preciso situar a relevância simbólica da história narrada. Durante quase todo o século XVII, o governo da Capitania Geral de Pernambuco tentou controlar e exterminar o Quilombo de Palmares, um conjunto de mocambos (aldeias) que chegou a congregar a mais de 20.000 escravos alevantados na Serra da Barriga (no atual estado de Alagoas, no nordeste do Brasil). A sua vinculação à épica da resistência outorga à saga de Palmares - e a seu principal ganga, Zumbi - um estatuto de mito. Isto não quer dizer que seja falso, mas que o discurso histórico sobre Palmares produz uma significação que vai além do fato narrado, destacando certos valores que promovem uma leitura da história transformadora do presente (BARTHES, 2001).

A significação deste episódio histórico tem sido objeto de disputas ao longo dos séculos: os primeiros cronistas coloniais tentaram mostrar o quilombo, inimigo do governo pernambucano, como um lastro arcaico que devia ser superado; no século XIX, os institutos históricos travaram debates regionais, ora mostrando os bandeirantes paulistas como heróis da integração nacional, ora mostrando os quilombolas como defensores da autonomia do Nordeste; já na metade do século XX, historiadores marxistas e ligados à militância negra (Edison Carneiro, Décio Freitas ou Clóvis Moura) reinterpretam Palmares como episódio de resistência épica e preservação da cultura africana nas Américas (REIs, 2004). Atualmente, o termo bantu Quilombo é um termo comum no português falado no Brasil, especialmente depois do reconhecimento destas comunidades na Constituição Federal de 1988.

A significação atual do quilombismo não designa apenas as instituições do povo Imbangala no século XVI (na atual Angola) nem os acampamentos de africanos alevantados contra a escravidão no Brasil colonial e imperial. Hoje, o quilombismo refere-se tanto as comunidades autônomas herdeiras daquelas tradicionais quanto,

Doutorando no Programa de Pós-Graduação em Sociologia na Universidade Federal do Rio Grande do Sul (UFRGS). E-mail: juliosouto2103@gmail.com. 
em um sentido lato, a todo movimento de luta de resistência cultural negra e autonomista contra o racismo contemporâneo (NASCIMENTO, 20o6, p. 117-125). Mais que a reminiscência de um passado distante, o vigor do quilombo de Palmares estende sua duração para além do século XVII. A luta de Palmares segue, tanto nos quilombolas que hoje enfrentam o poder do agronegócio e do desenvolvimentismo estatal no Brasil rural, quanto nos movimentos políticos de auto-organização das favelas contra o genocídio da juventude negra nas periferias urbanas.

Isto nos obriga a repensar nossos consensos sobre tempo histórico linear, a interação de fatos passados com o presente e a duração de acontecimentos que não terminaram definitivamente. Uma importante liderança quilombola contemporânea indaga: "qual a diferença entre o ataque dos colonizadores contra o quilombo de Palmares no século XVII e os atuais ataques praticados pelo grande capital contra as comunidades atingidas pelos megaprojetos, ditos 'empreendimentos', como, por exemplo, a construção da Usina Hidrelétrica de Belo Monte?" (BISPO, 2015, p. 21).

Visto assim, o quilombo de Palmares não acabou, porque ecoa com força em versos de poetas negros brasileiros como Solano Trindade ${ }^{1}$ ou Oliveira Silveira, ${ }^{2}$ ou mais recentes com o rapper Duguetto Shabazz ${ }^{3}$ ou o slammer Josemar Afrovulto. ${ }^{4}$ A significação de Zumbi dos Palmares, consagrada em 2008 com um monumento no centro de Salvador (BA), também ganhou telas de cinema e páginas de quadrinhos. Este trabalho memorialístico sobre o passado escravocrata, constituindo uma identidade negra como "ser na dor", é um traço recorrente da cultura política no Atlântico negro. Nos termos de Gilroy (2001), esta elaboração da figura do

\footnotetext{
- A longa epopeia Canto aos Palmares é considerada um texto fundador para a épica afro-brasileira da resistência quilombola: "Eu canto aos Palmares / Sem inveja de Virgílio ou Homero / e de Camões / porque o meu canto é o grito de uma raça / em plena luta pela liberdade" (TRINDADE, 1961).

2 "Palmares não é Palmares, / Palmares é Angola Janga. / Nem é só Zumbi ou Ganga / Zumba, senhores. Palmares / não é só um, são milhares”. Além deste Poema sobre Palmares (1987 [2012]), Oliveira Silveira foi membro fundador do Grupo Palmares, organização política negra que promoveu a data 20 de novembro como Dia Nacional da Consciência Negra, em memória da morte de Zumbi.

3 Seu tema Vamos pra Palmares é frequentemente repetido em saraus da periferia de São Paulo, com o refrão sendo coreado pelo público: "Mesmo que eu tenha que cruzar terras e mares / Eu vou pra Palmares, eu vou pra Palmares / Mesmo que no caminho me sangrem os calcanhares / Eu vou pra Palmares eu vou pra Palmares / Mesmo que os inimigos contra nós sejam milhares / Eu vou pra Palmares Eu vou pra Palmares". Letra do poema e vídeo da apresentação disponíveis em: http://zapslam.blogspot.com.br/2009/12/vamos-pra-palmares.html https: $/ /$ www.youtube.com/watch?v=YCP8CFfQNFU. Acessos em 11 de abril de 2018.

4 Poeta habitual nos slams de poesia falada de Porto Alegre, seu poema "Ontem me mataram" aborda as milhares de mortes de jovens negros nas periferias brasileiras, evocando a resistência palmarina: "E o nosso povo continua indefeso / talvez esperando surgir um novo... Zumbi! / Enquanto isso, dividimos esse peso em nossos ombros: / as quebradas, são senzalas ou são quilombos?" (Our people are still undefended / Perhaps expecting for a new Zumbi to rise / Meanwhile, we divide this weight on our shoulders: / The slums, are barracoons or are quilombos?). Vídeo da performance em: https://www.facebook.com/watch/?v=1563969777054420. Acesso em $11 \mathrm{de}$ abril de 2018.
} 
"sublime escravo" permite a coesão das comunidades diaspóricas afro-americanas para além da nostalgia de uma originalidade africana definitivamente perdida na middle passage, enfatizando o valor da resistência no sofrimento e os trabalhos de preservação de valores civilizacionais próprios em condições terrivelmente adversas. Por isso a memória de Palmares, especialmente a figura de Zumbi e o episódio da sua morte, ocupam um lugar proeminente para a memória afro-brasileira, ainda que talvez não seja tão hegemônico na história oficial da nação. Falamos, pois, de um episódio histórico com estatuto mítico, não no sentido de falseamento do real, mas pela sua relevância política e simbólica como acontecimento não fechado.

\section{Angola Janga: narrar o mito para que siga vivo}

Neste contexto, o quadrinista brasileiro Marcelo D'Salete decidiu propor uma nova abordagem junto às muitas já disponíveis:

Este não é o primeiro quadrinho sobre Palmares. Clóvis Moura e Álvaro de Moya (Zumbi dos Palmares, 1955), Antônio Trisnas e Aluan Alex (Zumbi - a saga de Palmares, 2003) Carlos Ferreira e Moacir Martins (A guerra de Palmares) já realizaram suas narrativas em quadrinhos sobre o fato. Na literatura e no cinema, Palmares também já foi imaginado por autores como João Felício (Ganga Zumba, 1961), George Landamane (Troia Negra, 1998) e Cacá Diegues (Ganga-Zumba, 1963, e Quilombo, 1984). Entretanto, devido à grandeza do evento, ele certamente merece novas interpretações (D'SALETE, 2017, p. 419).

Poderíamos dizer que já há histórias demais sobre Zumbi dos Palmares. Demais? Isso é relativo: quantos brasileiros conhecem de fato as nuances desta história. E mesmo que já fosse sabido: quantas histórias existem sobre Colombo, Cristo, Hitler ou o Rei Artur? E sobre Batman ou o Homem-Aranha? Quando personagens adquirem esse estatuto mitológico, parecemos sempre ávidos de mais uma narração, sem importar que já disponham da informação e possam prever o desfecho da história. O relevante não é a novidade da informação, mais a potência mítica do narrado, que faz sensível a variação na repetição. Contudo, o desafio permanece: como construir um romance gráfico cativante para o leitor brasileiro sobre Zumbi dos Palmares, um tema do qual já sabemos o desfecho?

A paisagem de relativa saturação temática lembra bastante a que enfrentou Alan Moore ao abordar Jack, o Estripador. Em uma cena de Os apanhadores de gaivota, o apêndice making-off de Do inferno, Moore escreve: "No outono de 1988, estou pensando seriamente a respeito de algo extenso sobre um assassinato. Os crimes de Whitechapel nem mesmo são levados em conta. Muito batidos. Óbvios demais" (MOORE; CAMPBELL, 2014, p. 16). Moore começa a se interessar pelo assunto ao conhecer a teoria de Stephen Knight, um investigador amador, que apresenta Jack, o estripador como parte de uma conspiração monárquica e maçônica. Mas 
para formular uma abordagem realmente interessante, Moore precisou recolocar os parâmetros narrativos.

Considerado o primeiro e mais famoso serial killer da história, a permanência de Jack, o estripador na memória coletiva se deve ao enigma irresoluto: quem cometeu os crimes? Como apontou Kracauer (2010) em ensaio seminal sobre o romance policial, o sucesso popular deste gênero se deve a sua estrutura de enigma. O detetive aparece como o herói racional de um mundo dessacralizado, onde a aplicação da lógica científica restabelece a ordem social alterada pelo crime. No caso de Jack, o estripador, o fracasso do detetive Abberline deixou margem para o surgimento dessa legião de detetives amadores que durante décadas tentaram achar a solução do mistério. Moore, desviando-se do caminho narrativo mais frequentado (quem o fez?), decide abordar os crimes como enigma resolvido e adensar o relato indagando as motivações, formas e significações próprias desse homicídio particular (por que o fez?), como metonímia de todos os homicídios cometidos pela humanidade (por que o fazemos?). Para isso, aceita sem hesitações a hipótese de Knight e apresenta de início ao médico maçom William Gull como o assassino, por encomenda da rainha Vitória. A narrativa não tenta desvendar quem foi Jack, o estripador, mas entender porque se cometeram os crimes, como agiram as diferentes personagens e grupos e quais as evocações poéticas de tais fatos.

Marcelo d'Salete propõe um deslocamento semelhante do mito de Palmares, adensando o enredo e elaborando os parâmetros narrativos já consolidados. A HQ Zumbi dos Palmares ${ }^{5}$ de Clóvis Moura ${ }^{6}$ e Álvaro de Moya ${ }^{7}$ (1955) serve como referência para entender os elementos básicos do mito no seu estado atual, tal como D'Salete o recebe: 1) no Brasil colonial, o quilombo dos Palmares é uma comunidade de africanos que fogem da escravidão e vivem livres na floresta; 2 ) após sucessivos fracassos em exterminá-los militarmente, a coroa portuguesa propõe um tratado de paz, que toleraria a autonomia relativa do quilombo e a liberdade dos ali nascidos, desde que se mantivesse a escravidão para o resto de africanos da colônia; 3) ante esta proposta, os quilombolas se dividem: a) o rei Ganga-Zumba aceita a proposta, aconselhado pelo vilão Ganga-Zona que negocia secretamente com os portugueses para converter-se no governador do quilombo; b) o jovem líder Zumbi recusa a oferta, considerando que seria uma cilada ou, no melhor dos casos, uma indignidade; 4) Zumbi se converte no ganga do quilombo de Palmares e começa uma resistência épica e trágica; 5) o bandeirante Domingos Jorge Velho comanda a expedição definitiva que destrói totalmente Palmares, da que Zumbi

5 História em Quadrinhos de 34 páginas, publicada na coleção “Aventuras Heróicas” da Editora La Selva (São Paulo, 1955). Adotando o estilo Fumetti popularizado pela editora Bonelli, esta HQ lembra as histórias de Tex Willer ou Zagor, muito populares no Brasil. A contextualização utiliza muitos painéis de texto extenso para providenciar informação histórica ou apresentar personagens e a narração gráfica privilegia as cenas de ação, como batalhas, lutas e assassinatos.

6 Historiador, sociólogo marxista e do movimento negro, foi um importante pesquisador da saga de Palmares.

7 Jornalista, artista e professor especializado em histórias em quadrinhos. 
sai ferido; 6) na perseguição final pela floresta, Zumbi é traído por um dos seus lugar-tenentes (Soares) e termina assassinado pelos portugueses.

Em essência, é o tema do traidor e do herói, no qual uma rebelião moralmente justa fracassa pelos interesses espúrios de indivíduos egoístas. Assim narrada, a arquitetura semiótica pode lembrar mitos clássicos de ocidente como o de Cristo ou Espártaco. A força deste tipo de mito para as mobilizações sociais insurgentes reside na coesão gerada por uma estrutura moral maniqueísta ("nós, os bons, contra eles, os maus") e a condenação suprema do traidor, julgado como pior do que o próprio inimigo, o que desincentiva as dissidências internas.

Angola fanga apresenta uma história de Palmares a partir desta estrutura mítica, mas indo além dela. As suas elaborações simbólicas e as trajetórias complexas das muitas personagens afastam o foco da figura monolítica de Zumbi, aprofundando as nuances morais e dilemas íntimos com a guerra colonial como pano de fundo. Sim, há heróis e vilões (ou momentos épicos e episódios de fraqueza), mas eles transitam entre a cidade e o quilombo e não sempre é fácil identificá-los. A narração abre espaço para a reflexão com as fraquezas e erros dos heróis, mas também permite mergulhar fascinados no labirinto de horror e ódio da mente dos vilões.

D'Salete desenvolve uma intrincada rede de enredos interconectados, combinando vertiginosos deslocamentos temporais do passado ao futuro, sequências de ação narradas com singeleza e maestria, e descrições pausadas de espaços e ambientes. Para costurar uma história ágil nessa malha, o autor se apoia em uma série de ícones visuais facilmente reconhecíveis, que conectam os diferentes capítulos como fios de Ariadne. Uma série de elementos paratextuais (mapas, cronologia, glossário e referências bibliográficas) ajudam a compreender o cenário e facilitam a leitura da história. Em definitivo, D'Salete consegue aproveitar o potencial deste particular meio expressivo, as histórias em quadrinhos, propondo uma reinterpretação do mito que talvez não fosse possível em outros meios.

O resultado é um monumental romance gráfico de mais de 400 páginas que atualiza o mito de Palmares e destaca entre as muitas narrativas sobre o mesmo. Vencedor do Prêmio Jabuti 2019, a HQ vem sendo saudada pela crítica nacional como "um clássico instantâneo"8 e "um acontecimento no mercado de HQs". 9 A obra já foi traduzida e publicada na França (editora Çá et Là), Portugal (Editora Polvo), EUA (Fantagraphics), Espanha (Flow Press) e Áustria (Bahoe Books).

Para a análise de Angola fanga nos apoiaremos, com fins comparativos, em outras obras do autor (Encruzilhada, 2011; Cumbe, 2014), na HQ Zumbi dos Palmares (Moura; Moya, 1955) e no romance gráfico Do inferno (Moore; CAMPBell, 2014). Com esta última, ainda que distante no tema, Angola fanga guarda interessantes paralelismos úteis para a interpretação. Os espelhamentos com a obra de Moore

8 CAstro JR., Chico. "Terra e Liberdade". Em fornal A Tarde. Salvador, 3 de abril de 2018.

9 SAвотA, G. "'Angola Janga', graphic novel de Marcelo d'Salete, é um épico que refaz a história de Palmares". O Estado de S. Paulo, 25 de novembro de 2017. 
passam por uma série de recursos e motivos: o enredo como um confronto de conspirações e espionagens, na qual a informação e o segredo são cruciais; o tempo da narrativa, uma complexa rede multidirecional com projeções ao futuro e regressões a acontecimentos prévios; a relevância do território e as cartografias ocultas que os coletivos constroem nele, em uma sorte de escrita sobre o chão e o ambiente; a caracterização desses coletivos de conspiradores por uma fala particular.

\section{Guerra de histórias e perspectivas}

Angola fanga se define como uma história sobre Palmares, não $a$ história de Palmares. Com esta indicação, o autor expõe que há traços ficcionais sobre consensos históricos documentados. Para manter o equilíbrio nesse limiar, há elementos que reforçam o efeito de verdade histórica, combinados com momentos de evocação onírica, que quebram a ilusão de realismo. Neste aspecto, Angola fanga se aproxima a Do inferno. Por exemplo, vemos que ambos romances gráficos incorporam como epígrafe de cada capítulo, em letra branca sobre fundo preto, alguma citação de documentos da época ou interpretação histórica dos fatos, relacionada com o tema do capítulo. Este elemento reforça o polo factual da narração. A superposição do histórico e do ficcional é mais fértil quando age nas margens do arquivo da memória oficial, lindando suas áreas ocultas e desvelando as relações de poder que o constituem.

Isto é, para narrar o destino de corporações oligárquicas opacas ou as suas vítimas, sujeitos subalternizados: ex-escravos revoltados no Brasil colonial, ou prostitutas assassinadas na Londres vitoriana. Em ambos os casos, o que se relata é a eclosão de uma subjetividade subversiva, causando uma descontinuidade na linearidade histórica e novas retrospectivas dissidentes. Comparemos como esse processo político de construção de subjetividades é narrado em ambos romances gráficos.

Ao preparar Do inferno, Alan Moore, como todos os detetives amadores que se debruçaram no caso, carecia do dado histórico central para qualquer relato sobre Jack, o Estripador: o nome do assassino. Sua narrativa costura fatos isolados não conclusivos, provas circunstanciais para expor a hipótese mais aceitável. No apêndice I, o autor comenta página a página os múltiplos dados de conhecimento público que embasa sua narração, destacando onde começam as especulações ficcionais: sabemos que em 1889, na rua Cleveland, existia um bordel masculino; sabemos que uma pessoa chamada Annie Crook, aparentemente implicada nos crimes, trabalhava em uma confeitaria na frente a esse bordel; sabemos que o príncipe Eddie foi acusado de ser cliente de tal bordel; mas não há provas de que o príncipe e a confeiteira tenham realmente se conhecido. Sabemos que existiu William Gull, que foi médico pessoal da rainha na época dos crimes, mas não é oficial seu envolvimento com a maçonaria. Quais os limites da objetividade histórica e da pesquisa documental? As relações de poder na produção e administração do arquivo. Não há nenhuma informação escrita sobre a vida das prostitutas assassinadas porque 
ninguém se preocupou em registrá-la. Por outro lado, há muita informação oficial sobre o médico real William Gull, mas uma sociedade opaca como a maçonaria não tem nenhum interesse em divulgar informações sigilosas dos seus membros.

Todos os debates históricos sobre o quilombo de Palmares enfrentaram esse tipo de limite para a pesquisa arquivística. Os arquivos escritos disponíveis foram produzidos e preservados pela coroa portuguesa, portanto, há abundante informação sobre o pensamento e as estratégias dos colonizadores, mas apenas há registros sobre a vida no quilombo ou a biografia dos seus heróis. Nos capítulos dois e quatro de Angola fanga se narra o nascimento de Zumbi no quilombo, o assassinato dos seus pais e seu cativeiro junto a um padre cristão em Porto Calvo, até que já menino foge de volta a Palmares. Este relato do nascimento e infância do herói está baseada na pesquisa de Décio Freitas, mas "ainda pairam suspeitas sobre essa versão" (D'SALETE, 2017, p. 421). Mais que pelo rigor histórico, esta versão da infância do herói é muito interessante do ponto de vista narrativo.

Em Angola fanga, a relação do Padre Antônio Mello com o menino Zumbi funciona como balanço à abordagem militar dos bandeirantes, para expor as duas relações possíveis entre colonizadores e quilombolas no contexto de guerra colonial: ou o extermínio puro e simples (como desejam os bandeirantes) ou a dominação por assimilação (como propõe a igreja). Nesse caso, a moral cristã impõe a missão paternalista de salvação das almas, como lembra o histórico sermão do Padre Antônio Vieira: "é melhor ser escravo no Brasil e salvar sua alma que viver livre na África e perdê-la” (VIEIRA, 2015, p. 35). No capítulo dois se produz essa estranha adoção, com Zumbi bebê salvado pelo padre cristão. A continuação desta ação se dá no capítulo quatro, quando o líder guerreiro quilombola lembra sua infância e fuga.

A relação entre Zumbi e o Padre Melo se fecha no sexto capítulo, com a visita dos quilombolas à vila. Este capítulo, aparentemente irrelevante para a ação do romance, é extremamente interessante para entender o contraste de formas de vida dos portugueses e dos africanos e compreender a opção de Zumbi ante a proposta da coroa portuguesa, recusando frontalmente a dominação assimilada. A narração nos leva, em um passeio pendular, entre a vila e o quilombo, com passagens narrativas de ritmo dilatado, ricas em descrições de ambientes.

No quilombo aparece a personagem Dara, uma menina que escuta a história da comunidade afro-brasileira pela voz do ancião Tata, desde o sequestro na África e a travessia nos navios até a fundação de Palmares. No ato de contar, o ancião constrói no cotidiano uma narrativa histórica do quilombo e da comunidade afrobrasileira que se contrapõe à narrativa brasileira de conquista e colonização. Nesse capítulo, o luminoso quilombo, com seus espaços abertos onde os humanos interagem com os animais e as plantas, contrasta com o escuro quarto da igreja onde repousa o padre, com sequências de planos curtos que focam círios, páginas da Bíblia ou as cicatrizes de Cristo na cruz. Como contraposição forte, o símbolo da cruz é associado a dor, feridas e sacrifícios, enquanto o símbolo da Ananse que 
Tata desenha na areia ante os olhos de Dara evoca a construção ardilosa de uma moradia que é também arma de caça, paradoxal união de proteção e ataque, alimento e couraça. Essa cosmologia complexa do cruzamento dos contrários sem síntese nem antagonismo contrasta com o maniqueísmo cristão: das páginas da Bíblia do Padre Antônio Mello, Zumbi resgata a passagem de Gêneses, na qual Deus separa a luz das trevas (D'SALETE, 2017, p. 199). O que provoca uma interessante conversa sobre salvação na fé e condenação no paganismo, a verdade única monoteísta e a legitimação do extermínio do diferente.

Se o conflito ontológico entre as perspectivas cristã e bantu estrutura quase toda a obra, este tema ganha destaque no capítulo sete ("Selvagens"), onde se apresenta o passado e a psicologia do bandeirante Domingos Jorge Velho. Aqui entendemos a epistemologia colonizadora, que reduzindo os diferentes à categoria de "selvagem", equipara na sub-humanidade indígenas e africanos. É impactante a primeira visão do sinistro bandeirante, em uma sombria barraca rodeado de mulheres indígenas sometidas, com um chapéu cobrindo o rosto e armado de facão e espingarda. A partir de um anel de ouro na mão do bandeirante começa um flashback que apresenta sua infância junto aos guaranis do vale do Parnaíba.

Nessa passagem acontece um interessante equívoco de perspectivas: os indígenas são percebidos pelo bandeirante a partir dos mitos portugueses, mas o próprio Domingos é apresentado com categorias da mitologia indígena. Ao escutar as lendas sobre os índios contadas pelo seu irmão mais velho, Domingos passa a acreditar que eles são antropófagos. Em uma cena na qual um menino guarani está comendo, Domingos vê sobre um prato de folhas um coração humano, junto a um olho e um dedo (D'SAlETE, 2017, p. 230). Na mesma página, uns quadros depois, vemos um peixe assado sobre o mesmo prato de folhas. Afinal, para a verdade da narração, a comida é um peixe ou um coração humano? Os quadros adjacentes ao prato de folhas fixam a subjetividade que produz a perspectiva: $o$ jovem bandeirante enxerga um coração, o jovem guarani um peixe. Sem ter como determinar a verdade última da cena, o juízo do leitor sobre esse prato dependerá da perspectiva adotada.

A mesma estratégia é utilizada, no sentido inverso, para apresentar o bandeirante da perspectiva indígena como o Anguêri. Como explica o glossário da obra, o Anguêri é uma entidade temível da mitologia guarani, um morto-vivo da floresta que ataca à noite e pode ter a forma de humano ou animal. Ao apresentar Domingos na perspectiva indígena, ele é visto como este monstro devorador de gente. Em uma escaramuça em que os bandeirantes exterminam um grupo de indígenas Oruazes, vemos a Domingos em êxtase entre os cadáveres, lambendo o sangue da sua faca (D'SALETE, 2017, p. 241). A assustadora duplicidade do Anguêri/Domingos volta a aparecer na batalha final contra Palmares, como uma sombra sobre a paliçada (2017, p. 304) ou um expressivo plano curto da mandíbula do bandeirante (2017, p. 309). Esse jogo de equívocos perspectivistas já tinha sido experimentado em uma história de Cumbe, quando um fazendeiro, na hora de estuprar uma 


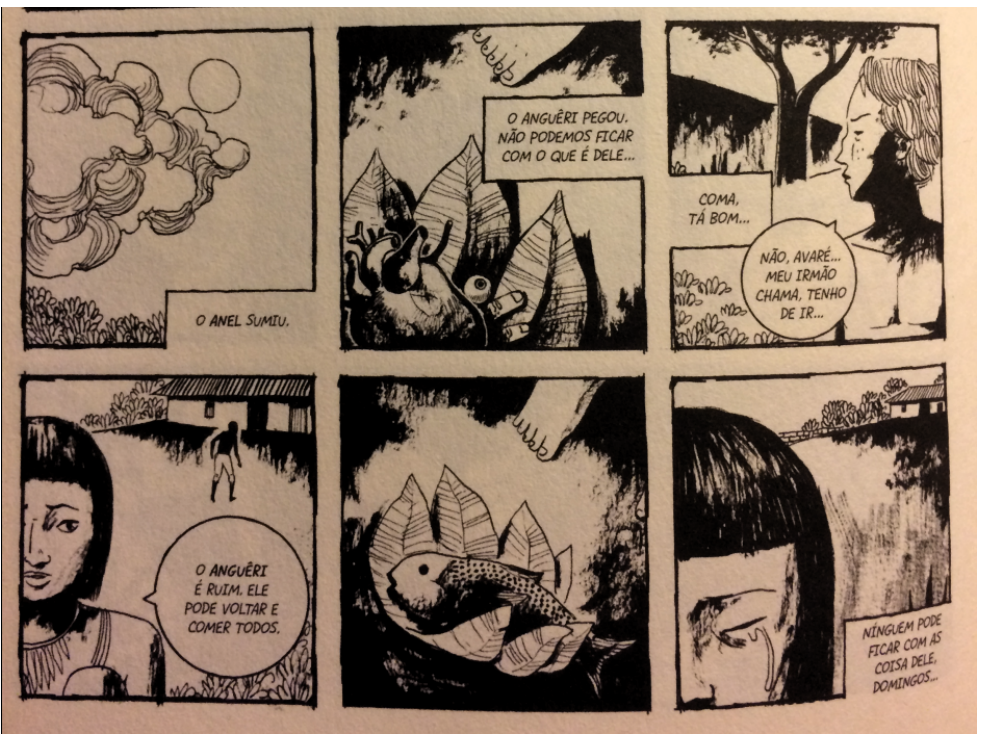

FigurA 1 - prato de comida: coração humano ou peixe? Fonte: D’SAlEte, 2017, pág. 230.

menina, é um quibungo da mitologia bantu, "um monstro grande com uma boca na nuca, que pega e engole quem tá perdido na mata” (D’SALETE, 2014, 142).

Em Angola fanga, entendemos que Palmares foi, além de uma guerra de corpos e armas, uma guerra de epistemes e mitos. Cegueira perspectivista sustentando um genocídio. Quando a narração se aproxima do colonizador, indígenas e africanos são percebidos como selvagens sub-humanos que podem ser exterminados sem consequências morais. É interessante de novo a comparação com Do inferno. Na Londres vitoriana, uma série de assassinatos e mutilações provoca o escândalo moral que detona o enigma inicial (quem fez isso?) e o mito de Jack, o estripador (quem é ele?). Como aponta Mbembe (2011), no regime necropolítico da colônia, o assassinato e o suplício são ferramentas normais da administração pública racional. Ordeiras, mortes negras não são enigma para detetive.

\section{Enredo de traições e densidade da morte: Zona, Joaquim e Soares}

Angola fanga marca uma transformação significativa na obra de Marcelo D'Salete, confirmando a maturidade de uma trajetória sólida e coerente. NoiteLuz (2008) e Encruzilhada (2016) eram obras ambientadas na atualidade das periferias de São Paulo. A nível estrutural, são um conjunto de histórias curtas autônomas parcialmente interconectadas, mas sem chegar a construir uma totalidade coesa nem complexos arcos de desenvolvimento das personagens. Os diferentes enredos curtos eram costurados a partir de ícones visuais marcantes: a marca de um celular, uma pichação ou uma medalha religiosa. Em Cumbe (2014) o autor adentra no mundo da escravidão no Brasil colônia. Com a estrutura narrativa ainda semelhante à de Encruzilhada e o cenário espaço temporal de Angola fanga, Cumbe de- 
senvolve muitos dos motivos e temas que aparecem na obra posterior. Em Cumbe vemos pouco o quilombo, priorizando histórias duríssimas de africanos escravizados lutando pela liberdade, como um prefácio sombrio para a luz solar de Palmares. A diferença estrutural que traz Angola fanga é a forma de romance gráfico, com capítulos que dialogam profundamente construindo um amplo arco coral.

Pensaríamos que Palmares é Zumbi, mas a biografia do rei não começa até o capítulo dois, com seu rapto aos poucos meses após seu nascimento. Só identificamos completamente quem ele é no capítulo quatro, ao descobrir a identidade desse bebê graças a uma faca ritual que foi entregue pelo seu pai. Estas informações são fundamentais para entender sua relação com o padre de Porto Calvo e a recusa da proposta de paz portuguesa (capítulo seis), dando profundidade ao trágico desenlace na hora da sua morte (capítulo dez). Entre estes capítulos sobre Zumbi, muitas coisas acontecem.

Como o autor sabe, a história de Zumbi não é a única relevante no quilombo: "Palmares não é só um, são milhares". Angola fanga se constrói como um romance coral enriquecido com histórias de personagens secundários de extrema importância. Em poucas páginas se consegue dar profundidade a cada um deles, utilizando flash-backs que capturam em episódios breves a essência psicológica de cada um. A caracterização minuciosa outorga dramaticidade a cada um dos atos individuais. No contexto de guerra colonial e governo necropolítico, vemos trajetórias humanas cheias de hesitações e fugas contraintuitivas, recusando os destinos definidos por esquemas maniqueístas. Três tristes traições mostram rachaduras nesse mundo bipolar.

O grande traidor da história é Zona, vilão conspirador clássico nos moldes do conselheiro ambicioso que, como Iznogoud, quer ser Ganga no lugar do Ganga. Nesta questão, Marcelo D'Salete é fiel ao relato histórico e ao mito consensualizado sobre a saga de Palmares. Nesta versão, o rei Ganga Zumba é um sujeito idoso e pusilânime que pretende evitar o confronto aberto com os portugueses, especialmente enfraquecido após a morte da sua mãe. O acordo de Cucaú (capítulos três e cinco) é oferecido como uma cilada para dividir os quilombolas, mas Zona vê nele uma oportunidade para converter-se no rei de um quilombo relativamente autônomo, ainda que assimilado ao reino de Portugal. O flash-back sobre sua infância, o apresenta como um egoísta perigoso para a comunidade, e ajuda a entender o assassinato do seu companheiro, facilitando o ataque a Aqualtune e impondo a rendição. A traição de Zona é simbolizada pela entrega da escultura de Chibinda Ilunga ao governador. Na história, esta estatueta é talhada e contemplada por Ganga Zumba, representando a reverência pela ancestralidade. Por isso seu furto e entrega aos portugueses carrega esse forte sentido de negação dos seus. Depois disto, Angola fanga não mostra em cena o final do desleal. Como contraste, é interessante notar que na HQ Zumbi (Moura e Moya, 1955) a execução de Zona por Zumbi é um ponto alto da narrativa. Para D'Salete, o silêncio sobre a morte de Zona aponta para a sua irrelevância histórica com o destino de Cucaú, destruído 
no momento de fraqueza. A conclusão que obtemos é que a Pax Romana entre quilombolas e portugueses é impossível, e a condenação moral de Zona ajuda a empatizar com o levante de Zumbi.

O português Joaquim, que termina lutando do lado dos quilombolas, simboliza a traição como revolta heroica. Sem nenhuma indicação de registro histórico sobre este indivíduo em particular, entendemos que representa na narrativa os muitos portugueses brancos que se tem constância que foram morar nos mocambos de Palmares. Joaquim, assim como Zona, é um indivíduo que abandona seu coletivo de origem para associar-se aos interesses do inimigo - seria, portanto, um traidor. Mas sua absolvição moral é mais uma mostra de que Angola fanga não pretende ser um relato imparcial sobre uma guerra simétrica. A trajetória de Joaquim é a fuga do lado opressor e indigno da história para assumir uma posição de abnegado e trágico mártir. Ainda que breve, sua trajetória é ambígua e psicologicamente densa.

As primeiras imagens de Joaquim o mostram temeroso dos quilombolas que visitam a vila, ambicionando capturá-los como escravos para satisfazer o desejo de seu pai - deste episódio sai vivo apenas pela bondade de Zumbi. No capítulo oito se adensa e complica a trajetória de Joaquim, com flash-back e avanço do enredo simultâneos. Neste capítulo o vemos como criança, filho de um senhor de engenho, sendo incapaz de jogar sal nas costas de um escravo chicoteado. A incapacidade para adotar o rol dominante no sistema escravocrata e a frustração por não poder cumprir o projeto do seu pai (devir senhor de engenho) é o principal nó de tensão psicológica da personagem, que se resolve no plano moral com a sua incorporação à frente quilombola. $\mathrm{O}$ seu relato passa pelo alistamento à partida do bandeirante Domingos Velho, ficando desacordado no primeiro combate. Ao sobreviver no mato, o comandante ameaça executá-lo por desertor, momento em que Joaquim decide se unir aos palmaristas (D'SAlEte, 2017, p. 287). Até o último momento os quilombolas duvidam dele (especialmente Andala, que tinha sido escrava na fazenda do seu pai) mas sua atuação na batalha de Macaco e depois a sua morte tentando defender os companheiros o libera de toda ambiguidade. Assim, é absolvido Joaquim em Angola fanga, um branco lutando ao lado dos negros, um traidor para os portugueses e um herói para os quilombolas.

O mulato Antônio Soares, braço direito de Zumbi em Palmares que no último momento entrega o líder, é a personagem mais enigmática e interessante, praticamente protagonista da narração de D’Salete. Como explica o glossário, "o registro sobre o mulato Soares aparece apenas uma vez nos documentos históricos. Sob tortura, ele foi o delator do esconderijo de Zumbi em 1695" (D’SAlETE, 2017, p. 415). Sem mais dados históricos, a mitologia de Palmares e a hagiografia de Zumbi tendem a fazer de Soares uma espécie de Judas, motivado pela fraqueza ante a tortura, a covardia ou o interesse pessoal pela própria liberdade:

Angola Janga se desvia desta imagem de Soares, apresentando uma trajetória individual cheia de arestas e ambiguidades de enorme poder evocativo. Ao mesmo 

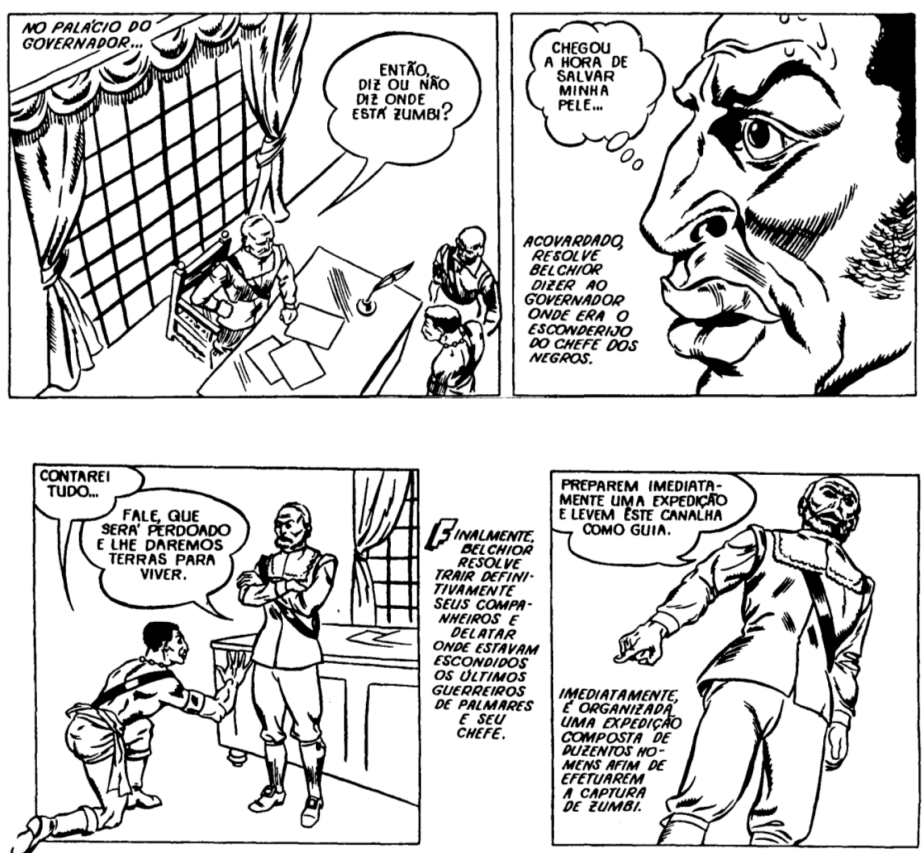

Figura 2 - Com o nome de Belchior, Soares aparece como o Judas quilombola. Fonte: MourA; MoyA, 1955, pags. 27 e 28.

tempo, Soares é mais um dos milhares de quilombolas anônimos sem registro nos anais históricos nem lembrados em cantos e poemas, mas que fizeram possível a epopeia. Destacado dessa massa de malungos sem nome, desde o início, a personagem é individualizada com fins narrativos. Sua caracterização visual é permanente e fácil de reconhecer: calção listrado, colar de búzios e dois " $\mathrm{X}$ " marcados com ferro cadente no peito.

Sua origem mestiça, filho de uma escrava estuprada pelo senhor do engenho não é irrelevante para a interação de Soares com o resto de personagens e sua significação na história, especialmente pela sua vinculação com Rodrigues, também mestiço, mas empregado como caçador de escravos fugidos ao serviço do senhor de engenho. O arco narrativo de Soares vem prefigurado pela profecia da Cuca (feiticeira) na metade da sua fuga, que com enigmáticas palavras prognostica: "Teu destino será grande e maldito. Você pode até ser livre, mas a perda e o esquecimento serão teus companheiros" (D’SALETE, 2017, p. 32-33). Junto a estas palavras enquadradas em off, os quadros vão mostrando um loop de imagens desconexas em um delírio místico: fogo - pássaros voando em círculos - símbolo Sona - olhos de mosca - paliçada - fumaça. Todos estes símbolos irão aparecendo ao longo da narrativa de Soares, tecendo uma continuidade nos enredos que não nos deixa sair deste momento profético.

A fuga de Soares, do engenho para Palmares, acompanhado do africano Osenga e perseguido pelo feitor Rodrigues, é o capítulo de abertura de Angola Janga. Esta 
posição de destaque no início do enredo indica qual é, nesta narrativa, o acontecimento mais potente em Palmares. Não é a liderança forte de Zumbi, as intrigas de Zona e Ganga Zumba ou a épica batalha final: é o estalo de revolta repetido por milhares de escravos que decidem fugir, arriscando a vida pela liberdade. $\mathrm{O}$ triângulo formado por Soares-Osenga-Rodrigues é interessante para revisitar o tema hegeliano do senhor e o escravo no contexto da plantação colonial. Como lembra Gilroy a partir dos escritos de Frederick Douglass, quando o confronto existencial sai do plano alegórico para ganhar concreção empírica, o sentido da parábola se inverte:

$\mathrm{Na}$ alegoria de Hegel, que corretamente situa a escravidão no inerente e central à sociabilidade moderna, vemos que um combatente totalmente concentrado nesta luta essencial prefere a versão de realidade de seu conquistador à morte e se submete. Ele se torna o escravo enquanto o outro obtém o domínio. A versão de Douglass é totalmente diferente. Para ele, o escravo prefere ativamente a possibilidade de morte à condição contínua de desumanidade da qual depende a escravidão da plantation (GIlroy, 2001, p. 308).

Essa preferência ativa da morte a escravidão é explicitada no primeiro capítulo por Osenga, sintetizada na remarcável página de dois painéis na qual o escravo revoltado encara com uma zagaia o feitor com sua espingarda.

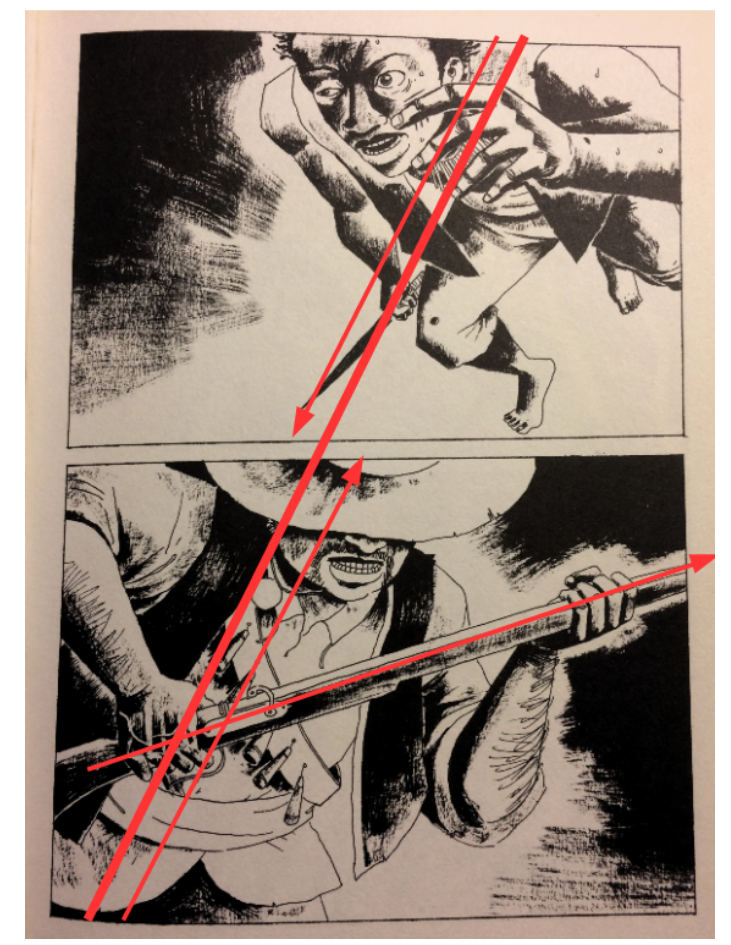

Figura 3 - Dialética do senhor e o escravo em contexto colonial. Fonte: D’SALETE, 2017, p. 49. Traços vermelhos nossos. 
Os retratos destacam pela sua força expressiva, em comparação com a caracterização prévia das personagens: as gotas de suor e os olhos assimétricos e exorbitados de Osenga, os dentes apertados e as veias saltadas no punho fechado de Rodrigues. O enquadramento e a posição dos corpos são irregulares, compondo uma diagonal descendente forte que cruza a página da esquina superior direita à inferior esquerda (ombro de Osenga-zagaia-cabeça de Rodrigues-medalhão-mão no gatilho) e cujo sentido se inverte pelo fuzil de Rodrigues, em posição diagonal ascendente de esquerda à direita. Essa diagonal sugere movimento convergente e expressa o confronto essencial dos dois personagens, que justapostos na vertical, se encontram no centro da página. A posição superior outorga todo o protagonismo da ação ao escravo revoltado, ainda que o fuzil do feitor apontando para a margem lateral direita antecipa o desfecho do confronto, que acontece fora de quadro, implícito na página seguinte.

Se a fuga firma a irmandade de Soares com Osenga, o assassinato do africano converte o feitor Rodrigues no seu principal antagonista, como veremos no desfecho da narrativa. Após a guerra e destruição de Palmares, reaparece junto aos soldados portugueses Rodrigues, que tinha estado ausente durante quase toda a obra. Isto permite colocá-lo frente a frente com Soares, uma vez capturado, amarrado e submetido a tortura. Dois mulatos na guerra de Palmares: Soares, escravo fugido e alevantado; Rodrigues, feitor ao serviço da coroa portuguesa. Chegamos ao enigmático clímax da personagem: por quê Soares entregou Zumbi?

Atendendo à sua trajetória completa, sua fidelidade ao líder descarta qualquer dúvida. Além de cumprir a delicada missão do envenenamento de Ganga Zumba, vemos Soares lutando bravamente do lado de Zumbi em sucessivas batalhas. Mas pouco antes de ele ser capturado pelos portugueses, já na decadência do líder vencido e perseguido na mata, uma sutil interação entre Zumbi e Soares pode mudar nossa interpretação do fato. Com Zumbi ferido descansando embaixo de uma árvore, Soares, Andala e Joaquim buscam água, e ao seu retorno ocorre o diálogo:

- SoARes: Muito bem, Zumbi acordou! / Trouxemos água e comida. / Ainda tem calhambola nos arrededores... / Vamos a achar esses malungos e nos preparar...

- Zumbi: Soares, não há mais Angola Janga. / Por que me trazer aqui?

- SoAres: Zumbi, Palmares ainda não terminou... Vamos fazer tudo de novo... / Começaremos indo atrás dos demais... (Soares se afasta com Andala).

- Zumbi: Espere Soares... / (Zumbi levanta a sua faca) / Fique com isto. / (Zumbi se adentra em uma caverna e Soares fica olhando a faca, com a boca aberta) (D’SALETE, 2017, p. 336-337).

No contexto geral da obra, essa faca tem um significado especial. No capítulo dois e quatro vimos como a arma pertencia ao pai de Zumbi, e foi guardada pelo seu avô até que foi entregue para o líder guerreiro. A faca, de um desenho estilizado facilmente reconhecível, traça uma linha de continuidade entre Zumbi e seus 
ancestrais, simbolizando a continuidade da luta. Renunciar a ela com tais palavras de desespero e desorientação, apresenta um Zumbi vencido e sem vontade de lutar - por isso a cara de desolação do seu amigo. No momento da tortura em que Soares entrega a localização de Zumbi para Rodrigues, parece que o estímulo que o leva à traição seria a promessa da própria liberdade.

Mas também poderíamos entender que, com o gesto, Soares pretende manter um mínimo controle dessa morte, oferecendo um bom fim para seu rei, líder e amigo. Lembrando seu estado de desistência, Soares desejaria poupá-lo das agruras e humilhação do suplício em praça pública, o fim da sua lenda. No contexto necropolítico, a amizade pode implicar tão tristes gestos de abnegação e irmandade. Lembramos a cena de Osenga encarando o feitor, zagaia contra espingarda, preferindo a morte ao cativeiro. A procura ativa da morte, por confronto suicida ou delação do amigo vencido, é fuga da condição desumana, é estratégia de resistência e dignidade.

A confirmação da absolvição moral de Soares acontece na sua última cena, quando em um momento de cumplicidade provoca a fuga de Andala, a companheira quilombola que ainda mantêm coragem para lutar (como se mostrará no último capítulo). Porém, é uma absolvição ambígua e triste. Nem herói nem traidor: um humano que nasceu em um contexto de terror, se recusou a viver como escravo e lutou pela sua liberdade, da melhor forma que pôde e soube.

Estas três traições, além de complexificar o esquema narrativo dualista da guerra, permitem revisar a densidade significativa da morte no contexto da necropolítica colonial. Recuperando a comparação com Do inferno, os assassinatos de Jack, o estripador ocuparam a memória coletiva inglesa como disrupção da ordem social e enigma misterioso. Com isso, Alan Moore tece a teoria da conspiração com o significado místico do homicídio, conectando o poder oculto da instituição monárquica, rituais maçônicos e a concepção temporal do ocultismo. Em Angola fanga se produz um deslocamento semelhante do significado da morte. A memória monumental de Palmares incide apenas na resistência épica ante um destino trágico inevitável, com a morte de Zumbi como consagração do herói e a delação de Soares como condenação do traidor. O tratamento narrativo da relação de Zumbi e Soares evoca o significado da morte na luta essencial entre senhor e escravo.

\section{O falar quilombola: idioletos e crioulização do idioma}

A caracterização dos coletivos em luta em Angola fanga se elabora em diversos níveis. Considerando que a cisão essencial no regime de plantação colonial é o racismo estrutural que separa negros e brancos, o cromatismo da pele dos personagens poderia ser utilizado como a ferramenta narrativa mais simples para separar os coletivos. Mas o romance gráfico é em preto e branco: o sutil tratamento de luzes e sombras com profusão de difuminados (técnica de pincel seco e borrões de tinta com contornos indefinidos) renuncia a elaborar a melanina como ele- 
mento narrativo, priorizando a potência expressiva da iluminação ambiental (luz do dia, da lua, sombras da floresta, interior de prédios ou cabanas) e a produzida por focos lumínicos artificiais intradiegéticos (círios, lampiões, fogueiras, tochas). Assim, não é raro ver o rosto claro (iluminado) de uma personagem negra, contrastando com o rosto escuro (sem luz) de uma personagem branca. A luz tem intenção dramática, não marca a cor da pele das personagens.

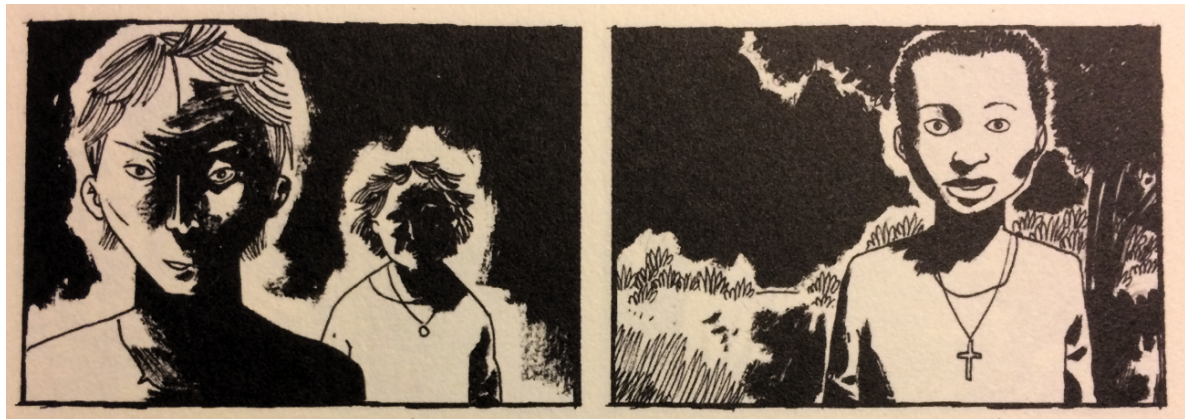

Figura 4 - Rosto escurecido de Furtado contra rostro iluminado de Zumbi. Fonte: D’SALETE, 2017, pág. 125.

A caracterização dos coletivos em luta passa por traços faciais, roupas e armamentos, de forma que mesmo sem ver a cor da pele, é fácil para o leitor distinguir um quilombola anônimo de um soldado português ou um indígena. Dentro dessa galeria racial, a individuação das personagens retratadas se apoia em elementos icônicos facilmente reconhecíveis (as marcas de Soares, as escarificações de Osenga, o penteado e colar de Zumbi, o medalhão e chapéu de Rodrigues, o parche no olho de Furtado, a careca e barba de Domingos Velho...).

Em Do inferno vimos recursos semelhantes de caracterização para identificar rapidamente os coletivos: os aristocratas com seus ternos e chapéus, os operários com suas roupas rasgadas, as prostitutas com seus longos vestidos e penteados de época. Mas a confusão é fácil nessa multidão de corpos cobertos e formas escuras que se movimenta entre a névoa de Londres. Alguns elementos de vestuário nos ajudam a distinguir indivíduos importantes como Gull (cartola) ou Abberline (chapéu-coco), mas no caso das quatro prostitutas protagonistas, distinguir visualmente uma da outra parece especialmente difícil. Esta homogeneidade visual das prostitutas é aproveitada no enredo em várias ocasiões, com a polícia ou os maçons confundindo umas com outras, até o ponto final em que duvidamos se Gull assassinou a Mary Kelly ou à sua companheira de quarto. Por isso ganha importância a caracterização das personagens pela sua fala particular (idioleto), como no caso da sueca Liz Stride, cuja fala é carregada de erros e hesitações ao não dominar o idioma. A preocupação obsessiva com a linguagem é uma marca de Alan Moore, que para este romance gráfico realizou uma intensa pesquisa para regis- 
trar as gírias e falas populares da Londres de finais do século XIX..$^{10} \mathrm{O}$ idioleto de cada personagem dá o tom psicológico do indivíduo ou dos grupos, como mostra o interessante diálogo do Doutor Gull com o cocheiro Netley (capítulo IV).

A utilização das variações linguísticas também é um recurso utilizado com sucesso em Angola fanga. Como falavam os quilombolas entre eles? Em que idioma? Sua fala seria diferente à dos portugueses, ou a fala de ambos grupos já teria se homogeneizado após dois séculos de escravidão nas Américas? Com base nas pesquisas históricas, D'Salete informa que as pessoas alevantadas em Palmares "eram africanos falantes do kimbundo, ovimbundo, umbundo etc. Uma parcela menor viria de outros locais. A cultura dos mocambos, então, era uma amálgama de tradições, em grande parte banto" (2017, p. 420).

Para manter a legibilidade e representar a diferença linguística dos quilombolas, D'Salete faz falar seus personagens em português, mas enfatizando os bantuismos presentes no idioma falado hoje no Brasil (com termos como malungo, missongo, calunga, cafundó) explicados em um glossário no apêndice. São conhecidas as marcas da africania no português brasileiro (PESSOA DE CASTRO, 2011) mas elas podem ser apagadas ou acentuadas, provocando a variação entre o idioleto dos quilombolas e os portugueses, mantendo a possibilidade de compreensão entre as personagens incluindo jogos de segredos e equívocos. Para o leitor de $\mathrm{An}$ gola fanga, esta decisão facilita a leitura fluída da narrativa, sugerindo reflexões sobre a dimensão linguística da relação colonial: dos processos de crioulização do idioma dominante até o contexto político necessário para a configuração de uma linguagem-nação, imaginando se um Palmares que tivesse permanecido independente até o presente teria produzido idiomas crioulizados comparáveis aos de países caribenhos (Glissant; Brathwaite, 2010).

\section{Lampejantes rupturas do cotidiano infernal}

A ruptura do tempo linear é outro traço marcante de Angola fanga. Como montagem narrativa, a analepse é utilizada muitas vezes para traçar o arco ou adensar a psicologia das personagens, como os flash-backs que mostram episódios da infância de Zona ou a morte dos pais de Zumbi. Mas outras vezes a descontinuidade do tempo é uma vivência compartilhada por leitor e personagem, como uma

\footnotetext{
10 Algumas destas marcas, difíceis de traduzir ou mesmo de compreender para o leitor atual, estão explicadas no apêndice I, por exemplo: “A expressão 'Hairy-Ford-Shire', um trocadilho um tanto obscuro com a pronúncia de Hertfordshire, é uma das inúmeras gírias vitorianas usadas para se referir à genitália feminina. Obtive essa informação do sr. Neil Gaiman, cuja boca imunda é capaz de proferir obscenidades geradas nos últimos sete séculos”. Também explica algumas expressões proferidas por personagens secundárias, apenas com intenção ambiental e sem nenhuma relevância para o enredo: "As exclamações registradas ao fundo nesta página são manifestações autênticas apregoadas em mercados na Londres vitoriana, de acordo com a valiosíssima coleção de retratos e observações contemporâneas London labour and the London poor, por Henry Mayhew (Penguin Books, 1985). O dialeto vindo de fora do quadro quando Marie entra no bar é conhecido como backslang (gíria do avesso), popular entre os verdureiros do East End durante a era vitoriana. Certas palavras eram ditas ao avesso...” (MOore; CAMPBELL, 2014, p. 7).
} 
analepse intradiegética. Nestas rupturas, a escravidão apresenta uma duração prolongada e o quilombismo aparece como um lampejo de corte para o eterno. Esse estalo da rebelião que rompe a continuidade cotidiana da plantação introduz uma dimensão de delírio ou epifania. Esse tipo de momento irrompe com as profecias da Cuca que escuta Soares no capítulo inicial, revivido em todo o seu arco, ou nas evocações marítimas de Zumbi ouvindo uma concha, ecos de Banzo, que ligam a infância ao momento da morte (capítulos quatro e dez). O sentido dessa temporalidade não homogênea é uma ontologia particular da duração no contexto colonial. A cosmovisão bantu do tempo, com a importância das profecias como costura do tempo, outorga um sentido coerente a essas analepses.

Aproveitando de novo a comparação com Do inferno, vemos momentos semelhantes de ruptura da continuidade temporal como delírio da personagem. No lugar da cosmovisão bantu, Moore explora a teoria esotérica da quarta dimensão, tema de interesse do médico maçom. Como montagem narrativa, isto nos permite conhecer a biografia do protagonista como um todo, no que se conectam momentos marcantes de infância, juventude e decrepitude. Mas há também a ruptura do tempo como vivenciada pela personagem. Evocando a história oculta, Gull apresenta uma leitura longa do tempo da perspectiva misógina dionisíaca, como quando evoca o altar pagão da deusa Diana que existia no lugar da catedral de São Paulo ou a derrota da rainha icena Boadiceia.

Mas a reflexão consciente contrasta com os momentos de epifania delirante, como a presentificação do deus Baal quando Gull sofre um derrame cerebral ou, com mais interesse para a comparação, na prefiguração alucinatória do futuro (nosso presente) vislumbrado no momento do último assassinato. Perplexo, Gull contempla nosso tempo como uma distopia esfriada, sem paixão nem vida. Situado de pronto em um escritório, rodeado de computadores, impressoras e calculadoras acionadas por indivíduos cinzentos.

Da perspectiva romântica vitoriana, essa é a visão apocalíptica do inferno contra a que Gull se rebela, perpetrando o crime para congelar o tempo na lenda. $\mathrm{O}$ feminicídio é apresentado como um gesto de poder solar contra a noite matriarcal, um instante de afirmação demoníaca da vida como potência e domínio que é preciso repetir para manter a ordem cósmica. Como essa pulsão homicida, Gull grita aos nossos contemporâneos: "Olhem para mim! Acordem e me contemplem! Eu estou entre vocês. Estarei ao seu lado sempre!” (MOORE; CAMPBELL; 2014, p. 21).

Esse mesmo recurso narrativo, a irrupção do nosso presente como sonho ou delírio futurista na narrativa histórica, é aproveitado por D'Salete com uma intenção completamente diferente. Em Angola fanga, o presente aparece no último capítulo, após a derrota de Palmares. Um zoom zenital arranca com a visão sideral do planeta e vai descendo o foco até nos situar espacialmente no Brasil, no mesmo lugar dos fatos narrados, mas no lugar da plantação encontramos uma megalópole de prédios pichados e vielas lúgubres. Sentada triste no chão, vestida com trapos 
e uns chinelos surrados, vemos a menina Dara, que conhecemos como habitante do quilombo de Palmares.

Um plano curto no seu rosto e, sem palavras, apenas com um olhar de espanto, Dara sente o chão ruir e cai em um abismo de escuridão que se funde em umas páginas alegóricas, que rodas de engrenagem estão moendo cana de açúcar, e o caldo escorrendo no conhecido engenho e a senzala, e um letreiro nos traz de volta ao tempo da narração: "Capitania Geral de Pernambuco, 1702". Ao acordar, Dara escuta a voz de uma anciã que descansa ao seu lado: "Tava sonhando, é? Você deve tá com febre!". Dara parece não ter acordado completamente, murmura: "A gente ainda pode... / Vou achar quem restou, ainda tem gente por aí". Mas a resignada companheira tenta impor o cruel senso de realidade: "Esquece isso, Dara! Não tem ngoma, nem passo de calhambola encafuado na mata... / Tu precisa lembrar só da cana, do açúcar, das cordas e chicotes". Em este caso, a prolepse intradiegética em forma de sonho permite traçar a continuidade da dominação racial entre o tempo de escravidão colonial e os nossos dias.

Com a visão da megalópole contemporânea, Encruzilhada irrompe em Angola fanga, apontando a persistência do racismo do século XVII ao XXI. Se a escravidão e o presente de dominação racial são um continuum infernal, o aquilombamento como ruptura rebelde é uma potência sempre presente, ao menos como virtualidade que pode ser atualizada a qualquer instante nas condições mais adversas: na narrativa, Dara acaba fugindo da senzala e unindo-se aos companheiros na mata, com Andala portando a retomada da estatueta de Chibinda Ilunga. A temporalidade que marca este desenrolar de acontecimentos lembra o paradigma descrito por Achile Mbembe, no qual as coisas e os acontecimentos envolvem-se uns aos outros, com histórias que têm um princípio, mas não forçosamente um fim:

Podemos, certamente, ser interrompidos. Mas uma história ou um acontecimento são capazes de prosseguir numa outra história ou num outro acontecimento, sem que haja necessariamente um encadeamento entre ambos. Os conflitos e as lutas podem ser retomados no ponto em que ficaram suspensos. Pode-se também retomá-los, ou ainda assistir-se a novos começos, sem que se sinta falta de continuidade, ainda que a sombra das histórias e dos acontecimentos antigos paire sempre no presente (MBEMBE, 2014, p. 251).

\section{Cartografias ocultas escritas no território}

Ao narrar uma guerra colonial, existiria a tentação de caracterizar os coletivos utilizando o fosso de separação entre as culturas com escrita e as culturas ágrafas, descrito como um "grande divisor" por etnólogos como Jack Goody (GolDMAN; LiMA, 1999). D’Salete não foge deste clichê antropológico, mas o tensiona introduzindo elementos dissonantes. O retrato dos colonizadores portugueses como "povo da escrita" é colocado em questão, restringindo a presença de livros aos ambientes eclesiásticos ou senhoriais. Nestes ambientes, a escrita é uma ferramenta 
política de dominação concretizada em bíblias, correspondências sigilosas, crônicas oficiais ou éditos reais. Mas, de fato, parece ilusório apresentar a bandeirantes ou camponeses portugueses como sujeitos letrados.

Do lado quilombola, precisamos de um conceito amplo de "escrita", não reduzido a alfabetos, livros e documentos, para poder compreender como Angola fanga desestabiliza esse grande divisor entre oralidade e escrita. Uma das referências culturais que D'Salete incorpora à narração é o Sona, tradição do povo tchokwe descrita no apêndice como um conjunto de símbolos, "desenhos formados por pontos e linhas sinuosas realizadas na areia e acompanhadas por narrativas orais" (2017, p. 418). No romance gráfico, vemos como o ancião Tata traz esses desenhos como um suporte gráfico para narrações e ideias, o que ajuda a crianças como Dara a fixar na memória esses ensinamentos. Além disso, Soares e Osenga encontram um símbolo Sona gravado em uma árvore, marcando um ponto importante para localizar, no meio da mata, o caminho ao quilombo. O mesmo símbolo tinha aparecido como visão na fogueira durante a profecia da Cuca e reaparecerá outras vezes ao longo da história, marcando uma continuidade temporal e territorial no espaço indiferenciado da floresta.

Uma marcação gráfica que impõe significação sobre uma continuidade indiferenciada: não é isso escrita? Precisamos alargar o sentido desta prática para poder ir além do grande divisor, que limita o conceito de "escrita" para fixar um abismo racial entre os civilizados e os bárbaros. Há muitas formas de escrever, como escreve Derrida sobre as picadas que os nômades Nhambiquara traçam em um território do tamanho da França, uma pista grosseira cujo traçado é quase indiscernível da floresta, abertura da diferença marcada pela repetição sobre o espaço indiferente da mata: "é difícil imaginar que o acesso à possibilidade dos traçados viários não seja ao mesmo tempo acesso à escritura” (DERRIDA, 1973, p. 133).

O símbolo Sona gravado na árvore se entrelaça a outros ícones visuais, como a silhueta do Morro da Barriga que vai aparecendo ao longo da narração. Quando o leitor é levado a acompanhar a perspectiva dos quilombolas, consegue se deslocar facilmente por essa cartografia de trilhas e mocambos, que permanece indiscernível para os bandeirantes. Da mesma forma que, em Do inferno, o maçom Gull nos mostra uma cartografia oculta de Londres marcada por obeliscos, sepulcros e templos misteriosos, cujas relações apenas são visíveis para os iniciados, em Angola fanga apenas os quilombolas conhecem o idioma das trilhas na floresta. Esse conjunto de rastros que territorializa o espaço, complexifica a separação entre a escrita artificial, os naturais acidentes geográficos e as marcas fortuitas não intencionais, assim como complica a separação conceitual entre mapa e território, ou representação e significado.

É uma escritura que não tem apenas o livro como suporte nem a tinta como veículo, mas circula da areia do chão às cortezas das árvores ou à pele lanhada dos quilombolas. Para entender esse idioma é preciso um processo de aprendizado que passa principalmente pela oralidade: lembremos do Tata contando histórias 
a Dara, enquanto desenha na areia. Ou as conversas de Soares sobre as cicatrizes, diferenciando as escarificações de Osenga, as feridas de combate de Zumbi e as marcas do senhor de engenho marcada a fogo no seu próprio peito. Permanente ou efêmera segundo o caso, há escrituras que se apagam com o vento e a chuva e outras que ficam no corpo toda a vida, impedindo esquecer o aprendido com dor.

\section{O aquilombamento como conspiração subversiva}

Com Angola fanga, Marcelo d'Salete apresenta uma narração singular e complexa da história do quilombo de Palmares, que pela sua significação política adquiriu um estatuto mítico. Este romance gráfico reconfigura os parâmetros narrativos mais consensualizados aproveitando técnicas próprias, que em alguns aspectos lembram a obra clássica Do inferno. Para apresentar o cenário geral da guerra colonial se mostram os conflitos ontológicos e epistemológicos que confrontam os mundos dos colonizadores e dos quilombolas, mas esse antagonismo central é atravessado por personagens complexas e vão além do maniqueísmo simples. Um dos motivos dramáticos centrais nesse contexto necropolítico é a densidade da morte na dialética do senhor e do escravo, que marca o destino dos protagonistas alevantados. Mais que um movimento político trágico carregado de épica, os quilombolas são descritos como sagaz conspiração que se costura com formas próprias de viver o tempo e o espaço, de falar e escrever idiomas indiscerníveis para o inimigo. As armas da conspiração, que no relato de Moore eram privilégio das oligarquias opacas, aqui são ferramenta de libertação. Por isso é importante destacar que o quilombismo, em Angola fanga, não é narrado como curiosidade histórica de quem estuda com erudição, mas como possibilidade lampejante sempre aberta à coragem, mesmo no pior dos infernos.

\section{Referências}

BArthes, Roland. Mitologias. São Paulo: Bertrand Brasil, 2001.

Bıspo, Antônio. Colonização, quilombos: modos e significados. Brasília, DF: s.n., 2015 .

D’SALETE, Marcelo. NoiteLuz. Via Lettera, 2008.

D’SAlete, Marcelo. Cumbe. São Paulo: Veneta, 2014.

D’Salete, Marcelo. Encruzilhada. [São Paulo: Leya, 2011]. São Paulo: Veneta, 2016.

D’Salete, Marcelo. Angola fanga: uma históra de Palmares. São Paulo: Veneta, 2017.

DerridA, Jacques. Gramatologia. São Paulo: Perspectiva, 1973.

Glissant, Édouard e Brathwaite, Kamau. El lenguaje-nación y la poética del acriollamiento. Uma conversación entre Kamau Brathwaite e Édouard Glissant. 
Em: SAlto, Graciela Nélida. Memorias del Silencio: literaturas en el Caribe y Centroamérica. Buenos Aires: Corregidor, 2010.

Goldman, Marcio; Lima, Tânia Stolze. Como se faz um Grande Divisor? Em: Goldman, Marcio. Alguma Antropologia. Rio de Janeiro: Relume Dumará - Núcleo de Antropologia Política, 1999.

Kracauer, S. La novela policial: un tratado filosófico. Buenos Aires: Paidós, 2010.

MвEmBE, Achille. Necropolítica. Madrid: Melusina, 2011.

Mbembe, Achille. Crítica da Razão Negra. Lisboa: Antígona, 2014.

Moore, Allan; CAmpbell, Eddie. Do Inferno. São Paulo: Veneta, 2014.

Moura, Clovis; Moya, Álvaro. Zumbi dos Palmares. São Paulo: La Selva - Coleção Aventuras Heróicas, 1955. Reedit. Betim: Prefeitura Municipal, 1995. Disponível em: http://lemad.fflch.usp.br/sites/lemad.fflch.usp.br/files/hq\%2Ozumbi_o.pdf Acesso em 30 de abril de 2018.

NAscimento, Beatriz. Eu sou Atlântica. São Paulo: IMESP, 2007.

Pessoa de Castro, Yeda. Marcas de Africania no Português Brasileiro. Africanias. Salvador, Universidade Estadual da Bahia, nº 1 , p. 1-7, 2011.

ReIs, Andressa Mercês Barbosa dos. Zumbi : historiografia e imagens. Dissertação de Mestrado em História. Franca: Universidade Estadual de São Paulo, 2004. Disponível em: http://www.dominiopublico.gov.br/pesquisa/DetalheObraForm.do?select_action=\&co_obra $=187$. Acesso em 30 de abril de 2018.

Silveira, Oliveira. Obra Reunida. Porto Alegre: IEL, 2012.

Trindade, Solano. Cantares ao meu povo. São Paulo: Fulgor, 1961.

Vieira, Pde. António. Obra Completa Padre António Vieira. São Paulo: Loyola, 2015

Recebido 7 de maio de 2019.

Aprovado em 20 de outubro de 2019. 


\section{Resumo/Abstract/Resumen}

Do Inferno a Angola Janga: história e mitologia do Quilombo de Palmares no romance gráfico de Marcelo d'Salete

\section{Julio Souto Salom}

Angola fanga (D’SALETe, 2017) narra a morte de Zumbi dos Palmares, líder do Quilombo mais importante da diáspora africana no Brasil, comunidade autônoma de africanos fugidos da escravidão. Esta saga é evocada em poemas, filmes, monumentos e memoriais, mas a história em quadrinhos providencia um meio com potencialidades específicas para costurar história e mitologia. D'Salete combina a pesquisa histórica e a poesia imagética para narrar uma história particular sobre esta mitologia viva. Para isso, são importantes: o enredo coral costurado por personagens não maniqueístas, o peso da morte na necropolítica colonial, a temporalidade não linear que faz durar o quilombismo até nossos dias, e a escrita do território com marcações cifradas. Com fins comparativos, comentamos as obras Cumbe e Encruzilhada (D'Salete, 2014; 2016), Zumbi dos Palmares (Moura; Moya, 1955) e Do inferno (Moore; CAMPBELL, 200o), atentando especialmente para as ferramentas de costura entre história e mitologia na história em quadrinhos.

Palavras-chave: Angola Janga, quilombo dos Palmares, romance gráfico, Marcelo D'Salete.

From Hell to Angola Janga: the history and mythology of the Quilombo de Palmares in Marcelo D'Salete's graphic novel

\section{Julio Souto Salom}

Angola fanga (D'SALete, 2017) tells of the death of Zumbi dos Palmares, leader of the most important Quilombo of the African Diaspora in Brazil, an autonomous community of Africans escaped from slavery. This saga is memorialised in poems, films, monuments and memorials, but comic-book provides a medium with specific potential for mixing history and mythology. D'Salete combines historical research and imagistic poetry to tell a particular story about this living mythology. For this, the following are important: the choral plot involving non-Manichean characters, the weight of death in colonial necro-politics, the non-linear temporality that makes Quilombism survive until the present day, and the writing of the territory with ciphered markings. For comparative purposes, we comment on the works Cumbe and Encruzilhada (D'SAlete, 2014; 2016), Zumbi dos Palmares (Moura; MoyA, 1955) and From Hell (MOORE; CAMPBELL, 200o), paying special attention to the articulating tools which connect history and mythology in comic-books.

Key Words: Angola Janga, Quilombo dos Palmares, Graphic Novel, Marcelo D'Salete. 
Del Infierno a Angola Janga: historia y mitología del Quilombo de Palmares en la novela gráfica de Marcelo D'Salete

\section{Julio Souto Salom}

Angola fanga (D’SAlete, 2017) narra la muerte de Zumbi dos Palmares, líder del quilombo más importante de la diáspora africana en Brasil, una comunidad autónoma de africanos que escaparon de la esclavitud. Esta saga es evocada en poemas, películas y monumentos; pero los cómics ofrecen un medio con potencial específico para unir historia y mitología. D’Salete combina la investigación histórica y la poesía imagética para contar una historia particular sobre esta mitología viva. Para ello son importantes: la trama coral cosida por personajes no maniqueos, el peso de la muerte en la necropolítica colonial, la temporalidad no lineal que hace que el quilombismo dure hasta nuestros días y la escritura del territorio con marcas cifradas. Con fines comparativos, comentamos las obras Cumbe y Encruzilhada (D'SAlete, 2014; 2016), Zumbi dos Palmares (Moura; Moya, 1955) y Del Infierno (MOORE; CAMPBELL, 200o), prestando especial atención a las herramientas de articulación entre historia y mitología en los cómics.

Palabras clave: Angola Janga, quilombo dos Palmares, novela gráfica, Marcelo D'Salete. 